\title{
Evolutionary Neglect of Aging: An Opportunity for the Behavioral and Social Sciences
}

\author{
David Ekerdt, Director, Gerontology Center; Professor of Sociology, \\ University of Kansas
}

0 everal years ago I found myself at a wedding rehearsal dinner in Kansas City, and seated beside me was the President of the Kansas State Senate. We fell into conversation and he asked me what did for work, and I said that I worked for the state, that I was a professor at the University of Kansas, in Lawrence. (At this point, it is important to know that my university has two primary campuses. Our Medical Center campus is in Kansas City and the main campus of the university is in Lawrence, 40 miles to the west.)

The conversation continued. And what did I teach? Well, about aging, gerontology. And the Senator was puzzled: "Aging? In Lawrence? Not the Medical Center?" So I went on to outline my teaching and research interests along with those of my colleagues in Lawrence, and the Senate President seemed happy to hear about all of it.

But I get this with some frequency: Aging-now isn't that a medical matter? So I dust off the same reply that I used at the rehearsal dinner to explain what we are teaching and doing about aging at the non-medical campus in Lawrence. And here I' $m$ going to reprise that line of conversation for you as a way to meet up with the theme of this Merrill Conference, in particular, the role of the social and behavioral sciences in addressing human development, potential, competence, and, yes, health in the second half of life.

One strategy would be to list the many topics, initiatives, breakthroughs, and achievements of the behavioral and social sciences in this regard. Such material, for example, is featured on the website of the National Institute on Aging and is surveyed in the pages of major handbooks (e.g., Binstock \& George, 2011; Schaie \& Willis, 2011). Rather than itemizing things, I am going to review with you part of a single theory in order to explain "what I am doing in Lawrence." One of the advantages of a good theory is that not only does it organize observation and explain the things observed, it can suggest what it is that we should do in the way of research and action-taking.

The author of this theory was the late Paul Baltes, a psychologist at the Max Planck Institute in Berlin, who was the leader of a sprawling international network of scientists concerned with human development across the life span. As a prologue to his general theory of life span development, "selective optimization with compensation," Baltes outlined the basic biological and cultural architecture of human development 
(Baltes, 1997). He argued that this architecture is progressively less complete across adulthood and into later life. This contention about incompleteness is what I will review here. As I proceed, I don't want it to escape your notice that I am a sociologist showcasing the theoretical ideas of a psychologist in order to endorse their applicability to many disciplines.

\section{Evolutionary Fitness Declines}

Three principles support the proposition about incompleteness (see Figure 1). As the first principle, Baltes observed that the benefits resulting from evolutionary selection diminish with advancing age. The exact shape of the left-hand the remainder of this presentation, the theory is that of Paul Baltes, but the glosses are my own.) The hook that I have used in teaching evolution and aging on both $\mathrm{KU}$ campuses and to the public is that "You are not supposed to live past 40." I explain that evolutionary selection operates to make successive generations of the organism better and better at reproduction. However, once reproduction is underway, the force of natural selection diminishes and abnormalities begin to accumulate in the genome. Humans begin to see the expression of these flaws already in their 30s, and multiple conditions, impairments, and diseases only become more appar-

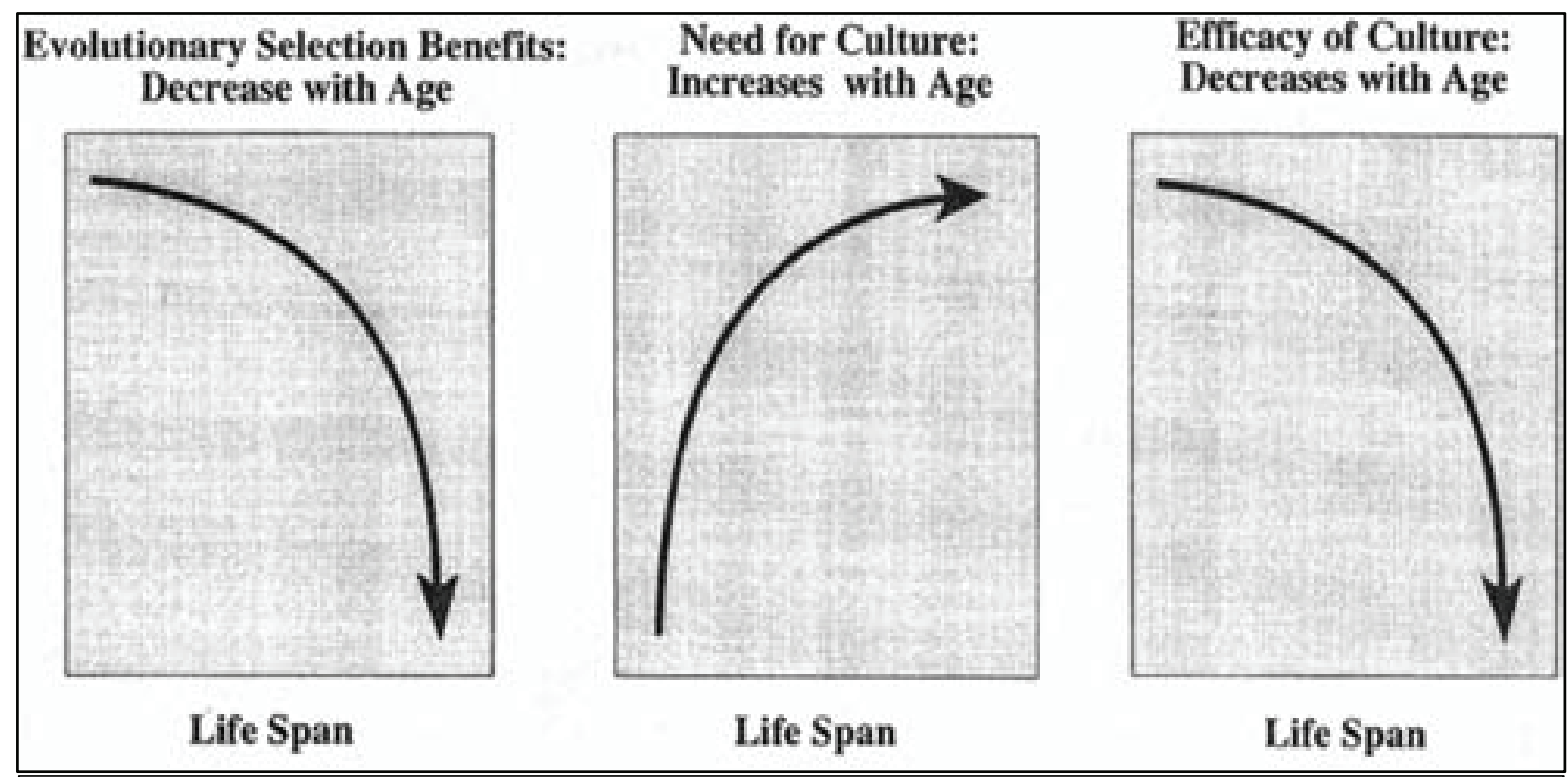

Figure 1. Schematic representation of three principles governing the dynamics between biology and culture across the life span. From "On the Incomplete Architecture of Human Ontogeny: Selection, Optimization, and Compensation as Foundation of Developmental Theory," by P.B. Baltes, 1997, American Psychologist, 52, p. 367. Copyright 1997 by the American Psychological Association. Reprinted with permission.

curve that depicts this principle in Figure 1 does not matter for purposes of this argument. The main takeaway is this: that as life goes along, there is less fitness from our biological design. (For ent in subsequent decades (Austad, 2009; Olshansky \& Carnes, 2001). About all this falling apart, I don't need to go into detail. 
Aging, therefore, is the "afterwards" of life's big objective for all animals - the production of offspring. In human scale, we have a biological design to carry us to 40 or 50 as we generate, parent, and (according to one hypothesis) grandparent the next generation, and then we are obsolete, biologically pointless. My listeners generally find this message depressing. Nonetheless, I push on to tell them that this is actually good news! And for two reasons.

For one thing, the bodily manifestations of aging that we dislike (such as wrinkles, sagging skin, joint problems, hearing deficits, hypertension, diabetes, prostate trouble, osteoporosis, etc.) are ultimately not our fault! They are part of our biological inheritance. Yes, you are falling apart, but it's probably nothing you did (unless you accelerated things with bad choices). Rather, you can blame all that accumulated junk in the genome.

For the other silver lining, recall that I said that there is evolutionary indifference to post-reproductive life, that it's just an "afterward." So we are not designed to last, but the good news, at the same time, is that is that we are not designed to fail. Evolutionary neglect of this period of life of means that aging does not have a genetic program. There is no design, plan, scheme, timetable reliably winding us down. If we are not destined to deteriorate on schedule, then there are many ways to have a beneficial effect on the rate of decline or the onset of symptoms. There is a dividend of evolutionary neglect, and this is welcome news, indeed! With some effort and some luck, human life can extend well past the reproductive period-we can live past 40 or 50 or twice longer still. And this space left by evolutionary neglect should be of enormous interest to the behavioral and social sciences.

Though I am here to discuss the second half of life, I must recognize that there is likewise enormous scope for the behavioral and social sciences in the biologically "fitter" front end of life. Humans are born with a radical "worldopenness," underdeveloped relative to other species with drives "unspecialized and undirected" (Berger \& Luckmann, 1967: 47-48). The process by which human organisms become human beings takes place in specific environments, cultures, and social orders, so to say, in the case of humans, that the environment is an "adjunct" or "input" to growth and maturation is far too tepid a way to put it (Dannefer \& Kelley-Moore, 2009). We derive our very humanity from the social world around us, and so the life course is socially constructed from its first moments.

It is an amazing transformation. Little drippy people with unregulated emotions are trained, habituated, socialized, and educated to codes of behavior, knowledge, and concrete social realities (Elias, 1978). They become sufficiently civilized to attend prom and then matriculate at our great universities for polishing. How this works - the creation of adults - for good or ill, and how it could be done better, is a wide field for the behavioral and social sciences. How this works also seeds potential direction for the rest of life.

\section{Culture Compensates}

Resuming discussion of the second half of life: What, then, compensates for the falloff in evolutionary benefit? Bal- 
tes's second principle (Figure 1, middle) is that there is an age-related increase in the need or demand for culture. "Culture" here is shorthand for all sorts of knowledge-based resources: psychological, economic, material, technical, symbolic. It encompasses advantages from public health, educational strategies, literacy, human rights, medical care-all the fruits of human ingenuity. Not everyone has equal access to these resources, and so advantage (or disadvantage) cumulates across the life course leading to disparities in well-being and function (Herd, Robert \& House, 2011).

The progressive importance of culture-as-compensation across adulthood can be readily imagined with instances of technological assistance, such as hearing aids and dental restorations. But let me illustrate with some aspects of social structure.

Example: The seniority principles that are built into many work organizations. As a reward for loyalty and past productivity, older workers in such programs are compensated with a rising wage and sheltered from direct competition with younger workers who may have more strength and stamina. In this way, senior workers' experience, skills, and institutional knowledge are conserved for the organization.

Example: Social security systems and pension arrangements that guarantee a level of financial security in later life. Unlike the long horizon facing younger economic actors and savers, older people have less time to recover from financial missteps or catastrophic losses. Women, because of their longer lives, typically lower earnings, and greater chance of widowhood, stand in even greater need of insurance against want and privation in retirement (Ekerdt, 2010).

These two examples regarding seniority and social security programs warrant a comment. The last 30 years, unfortunately, have seen a rising ideology that aims to undo these organizational and financial arrangements-arrangements that collectivized risk (Hacker, 2006; Schulz \& Binstock, 2006). In their stead, individuals are living with greater uncertainty under the banner of "individual responsibility," an ideology that brings more risk-employment, investment, and financial jeopardy-and more stress into the lives of adults.

Example: Social and especially family support. The hallmarks of adulthood are independence and agency. But in later life there comes a time of growing dependence on others for the accomplishment of daily tasks. People fiercely resist this dependence (just try to convince an elder to stop driving), but by the $70 \mathrm{~s}$ and $80 \mathrm{~s}$ some supportive measures have typically begun. In our culture, this support responsibility falls to families and, by and large, they knock themselves out (National Alliance for Caregiving and AARP, 2009). At often great cost to themselves, they step in to manage money, provide rides to a medical appointment or the store or church, help with household maintenance, and even undertake personal and bodily care of older relatives. No doctor writes an order for this, but it is what keeps people alive. These caregiving activities are also a deposit into culture because they are, in turn, a lesson to the next generation. 
Example: The motivation of health behaviors. Just about all the advice about healthy practices that we will ever need we learned in junior high: Eat a healthy diet, exercise, get enough sleep, don't smoke, drink in moderation, practice safe sex. Young people, biologically fit and feeling themselves to be indestructible can be heedless of this guidance. But, beginning in middle age, this advice needs restatement with even more effective techniques of persuasion. Especially to men, who are less likely than women to engage in preventive health and self-care, particularly if they have strong masculinity beliefs (Springer \& Mouzon, 2011).

How can we get people to doubledown on such no-brainers as exercise and healthy eating so as to delay the raft of diseases that flow from our comfortable affluence and the marketing of harmful products? Behavioral change toward better health has been identified as the top challenge for social science (Giles, 2011). Harvard University recently assembled a panel of scholars to articulate the hardest, unsolved problems that social scientists should tackle, and this is what topped the top-ten list: How can we induce people to look after their health? These efforts are all the more urgent with reports that advances in life expectancy have stalled in some segments of the population. In one recent report (Kulkarni et al., 2011), life expectancy in $80 \%$ of U.S. counties fell in standing between 2000 and 2007 against ten benchmark nations with the best life expectancies. Women have fared more poorly than men. A good number of these counties are economically disadvantaged, but progress can be made every- where with public health campaigns and innovative messaging to address smoking, obesity, and other preventable causes of death.

Having cited these four examples about the rising need of culture, I'm wary of painting later life as a time of increasing neediness and dependence. This is not a one-dimensional season of life. Through their civic engagement, philanthropy, and family involvement, older people make great contributions to society, community, and kin, but that is a topic for another time (MorrowHowell, 2010).

\section{But Culture Is Less Efficient}

So with advancing age, evolutionary benefits weaken, but culture compensates. However, there is a third principle about incompleteness (Figure 1, right). According to Baltes, there "is an age-related loss in the effectiveness or efficiency of cultural factors and resources" (p. 368). There remains plasticity and the potential for life long development, but the scope of plasticity narrows with age and interventions wane in power.

Example: Learning continues, but it is compromised. Older adults, owing to declines in sensory, cognitive, and physical abilities, learn more slowly and have more problems acquiring new knowledge. In a complicated world, with ever more sophisticated information flowing at us--technical, legal, financial, medical-we have to find ways to modify speech, written materials, instructions, visuals, and learning conditions so that older adults are not left behind, so that their full participa- 
tion in our increasingly technological world is not compromised (Berg, 2008).

Example: The built environment. Our houses - they have been great places to live, raise a family. Bedrooms upstairs; family room, laundry, and workshop down in the basement. Outside: nice sized yard, big driveway, quiet streets, no busy traffic. This form of housing, suburban housing, is where over $50 \%$ of older people reside, but it lacks many of the features, qualities, and services necessary to support the wellbeing of older persons (Frumkin, Frank \& Jackson, 2004). Traditional suburban design loses its efficacy when one cannot climb stairs, clear snow, mow the grass, or drive, leaving people isolated on islands of property that no longer fit their capacities. This is an issue-optimal places to live-that needs the creativity of, among others, architects, designers, and urban planners.

Example: The stuff inside that house. Those possessions were all acquired and accumulated to furnish daily life or support the development of the self (that fishing gear, those gardening tools). Some of it displayed one's station in life (sets of china, shelves groaning with impressive books). However, the ability to manage and maintain a houseful of stuff can come into question, its disposition a matter of concern and a potential obstacle to living in a more suitable place (Smith \& Ekerdt, 2011). How do we convince people to release this material convoy that has sustained their identity?

So, the goods and affordances that were necessary and supportive only 10 or 20 years earlier - the information one needs to have or master, that comforta- ble property and all its contentsbecome less helpful.

My last example is not of things supplied from without, but a resource from within: the sense of time and how much of it is left. Longer life expectancies (the biblical four-score years) allow adults the imagination of things that could yet happen or could yet be tried, second chances, reinventions, projects, and dreams. This is the great shining promise of retirement, for which people start saving decades in advance.

Yet in later life people begin to sense their finitude. Research has shown that the subjective sense of time-growingshort can have "profound effects on basic human processes, including motivation, cognition, and emotions" (Carstensen, 2006: 1913). As one outcome, intimations of mortality can channel goal-directed behavior and so promote additional personal development even as the life-world narrows. Death, the great deadline, makes things matter (Baars, 2010). However, another outcome can be a sense of despair and frustration about what is no longer possible. In either direction, the resolution of this problem of meaning will have consequences for those to whom our lives are linked. In these matters, if you hear me suggesting a role for social psychology and mental health professionals, I am. If you hear me suggesting a role for the humanities, I am doing that, too.

\section{Conclusion}

To sum up, this architecture, as outlined by Baltes (1997), sets the possibilities and limits on human development over the life course. The human life course in its later reaches is a social and 
cultural construction, but certainly one that we can manage and direct. I said at the outset that a good theory conveys a program of action. In the case of human development across adulthood, the research program for the social and behavioral sciences requires, as a basis, great skill in the characterization and interpretation of within-individual change. This topic has already been a conference focus of the Merrill Advanced Studies Center (Little, Bovaird \& Card, 2007).

And the theory-driven, action program is this: (1) Appreciate (but do not exaggerate) the contours of declining bodily fitness. (2) Analyze how cultural habits, social structures, human ingenuity, and a will to survive extend life and promote welfare. (3) Devise ways by which this support can be optimized, to the end. For the behavioral and social sciences, there is plenty to do. And in the future there is really going to be plenty to do. This year, 75 million Baby Boomers-nearly one-quarter of the American population-begin to turn 65 . The members of that cohort are going to be a large and irresistible market. They are going to buy things, want services, and seek experiences. A workforce will need to be trained to serve that market.

And for that market, the best of our social and behavioral work on life-span development can be translated into products, services and experiences. For example: settings for learning and selfdevelopment; user-friendly communications and computing technologies; furnishings and modifications for livable homes; effective health promotion programs, especially for the underserved; techniques and devices for self-care, selfregulation, and stress reduction; meth- ods for building the skills of older drivers; programs to support volunteer caregivers; community organizations that can harness the talents and altruism of seniors who are themselves volunteers; management techniques for the accommodation of older workers; tools from behavioral economics to assist people in making financial choices and in evaluating risk; investment and insurance products designed to secure financial well-being; and modalities that harness social networks for the transmission of information, resources, and influence.

What am I doing in Lawrence? I'm attending to something-later life - that is a not a disease, but rather normal part of life, one with considerable potential for development, productivity, and good health.

\section{References}

Austad, S.N. (2009). Making sense of biological theories of aging. In V.L. Bentsen, M. Silverstein, N.M. Putney \& D. Gans (Eds.), Handbook of theories of aging (pp. 147-162). New York: Springer.

Baars, J. (2010). Philosophy of aging, time, and finitude. In T.R. Cole, R.E. Ray \& R. Kastenbaum (Eds.), A guide to humanistic studies of aging: What does it mean to grow old? (pp. 105120). Baltimore: Johns Hopkins University Press.

Baltes, P. B. (1997). On the incomplete architecture of human ontogeny: Selection, optimization, and compensation as foundation of developmental theory. American Psychologist, 52, 366-380.

Berg, C.A. (2008). Everyday problem solving in context. In S.M. Hofer and D.F. Alwin (Eds.), Handbook of cognitive aging: Interdisciplinary perspectives (pp. 207-223). Sherman Oaks, CA: Sage.

Berger, P.L. \& Luckmann, T. (1967). The social construction of reality: A treatise in the sociology of knowledge. Garden City, NY: Anchor Books.

Binstock, R.H. \& George, L.K. (Eds.). 2011. Handbook of aging and the social sciences ( $7^{\text {th }}$ ed.). Boston: Academic Press. 
Carstensen, L. L. 2006. The influence of a sense of time on human development." Science 312, 1913-15.

Dannefer, D. \& Kelley-Moore, J.A. (2009). Theorizing the life course: New twists in the paths. In V.L. Bengtson, M. Silverstein, N.M. Putney \& D. Gans (Eds.), Handbook of theories of aging (pp. 389-412). New York: Springer.

Ekerdt, D. J. (2010). Frontiers of research on work and retirement. The Journals of Gerontology Series B: Psychological Sciences and Social Sciences, 65, 69-80.

Elias, N. (1978). The civilizing process, Vol.1. The history of manners. Oxford: Blackwell.

Frumpkin, H., Frank, L. \& Jackson, R. (2004). Urban sprawl and public health: Designing, planning and building for healthy communities. Washington, DC: Island Press.

Giles, J. (2011). Social science lines up its biggest challenges. Nature 470, 18-19.

Hacker, J.S. (2006). The great risk shift: The assault on American jobs, families, health care, and retirement and how you can fight back. New York: Oxford.

Herd, P., Robert, S.A. \& House, J.S. (2011). Health disparities among older adults: Life course influences and policy solutions. In R.H. Binstock \& L.K. George (Eds.), Handbook of aging and the social sciences ( $7^{\text {th }}$ ed.) (pp.121-134). Boston: Academic Press.
Kulkarni, S. C., Levin-Rector, A., Ezzati, M., \& Murray, C. J. L. (2011). Falling behind: Life expectancy in U.S. counties from 2000 to 2007 in an international context. Population Health Metrics 9, 16-27.

Little, T.D., Bovaird, J.A. \& Card, N.A. (Eds.). (2007). Modeling contextual effects in longitudinal studies. Mahway, NJ: Lawrence Erlbaum.

Morrow-Howell, N. (2010). Volunteering in later life: Research frontiers. The Journals of Gerontology Series B: Psychological Sciences and Social Sciences 65, 461-469.

National Alliance for Caregiving and AARP. (2009). Caregiving in the U.S. 2009. Bethesda, MD: National Alliance for Caregiving.

Olshansky, S.J. \& Carnes, B.A. (2001). The quest for immortality: Science at the frontiers of aging. New York: Norton.

Schaie, K.W. \& Willis, S.L. (2011). Handbook of the psychology of aging ( $7^{\text {th }}$ ed.). Boston: Academic Press.

Schulz, J.H. \& Binstock, R.H. (2006). Aging nation: The economics and politics of growing older in America. Westport, CN: Praeger Publishers.

Springer, K.W. \& Mouzon, D.M. (2011). “Macho men" and preventive health care: Implications for older men in different social classes. Journal of Health and Social Behavior 52, 212-227.

Smith, G.V, \& Ekerdt, D.J. (2011). Confronting the material convoy in later life. Sociological Inquiry 81, 377-391. 